\title{
ОЦЕНКА ТЕМПОВ РАЗВИТИЯ МАЛОГО И СРЕДНЕГО ПРЕДПРИНИМАТЕЛЬСТВА В РОССИЙСКОЙ ФЕДЕРАЦИИ
}

\author{
(c) 2019 Далбаева Валентина Юрьевна \\ кандидат экономических наук, старший преподаватель кафедры банковского дела и ценных бумаг \\ Байкальский государственный университет, Россия, Иркутск \\ E-mail: dalbaeva_v@mail.ru \\ (c) 2019 Ангаева Евгения Юрьевна \\ аспирант кафедры экономики и государственного управления \\ Байкальский государственный университет, Россия, Иркутск \\ E-mail: ongor1986.86@mail.ru
}

В очередном ежегодном послании Президента Российской Федерации Владимира Путина Федеральному Собранию от 1 марта 2018 г. были установлены целевые ориентиры роста для сектора малого и среднего предпринимательства к 2024 г.: доля малого и среднего предпринимательства в ВВП $40 \%$, численность занятых на малых и средних предприятиях -25 млн. человек. Для достижения установленных ориентиров необходимо, в первую очередь, провести исследование темпов развития предпринимательства в стране за предыдущие периоды времени и определить, насколько они обеспечивают выполнение поставленной цели. С целью максимально точного определения уровня и темпов развития данного сектора экономики для анализа использовались отчетные данные сплошных федеральных статистических наблюдений за деятельностью субъектов малого и среднего предпринимательства за 2010 и 2015 гг. Результаты проведенного анализа показали недостаточность достигнутых в исследуемом периоде темпов развития предпринимательства для выполнения целевых ориентиров.

Ключевые слова: Субъекты малого и среднего предпринимательства; темпы развития малого и среднего предпринимательства; целевые ориентиры развития.

В послании Президента Российской Федерации Владимира Путина Федеральному Собранию от 1 марта 2018 г. в комплексе задач, решение которых сможет обеспечить прорывное развитие экономики, указывается задача по развитию малого предпринимательства. В послании Президента эта задача отнесена к масштабному резерву экономического роста, вклад которого в создание ВВП к 2024 г. планируется довести до 40\%, а число занятых в этом секторе экономики увеличить до 25 миллионов человек.

Безусловно, для выполнения поставленной Президентом задачи потребуется немало усилий, поскольку в настоящее время доля малых и средних предприятий в ВВП далека от заданной цели и значительно отстает от показателей экономически развитых стран (табл. 1).

Как видно из данных таблицы 1 , уровень развития малого и среднего предпринимательства в России отстает от зарубежного опыта. В частности, доля малых и средних предприятий в ВВП экономически развитых стран составляет 50 и более процентов (США - 62\%, Япония -
63\%). В России в 2014 г. этот показатель был равен 21\%, а по данным Минэкономразвития за 2017 г. $-22,3 \%$ [3].

Для определения потенциальных возможностей роста малого и среднего предпринимательства необходимо исследовать динамику основных показателей деятельности этого сектора экономики за предыдущие годы. Для получения наиболее полных и достоверных данных обратимся к результатам сплошного федерального статистического наблюдения за деятельностью субъектов малого и среднего предпринимательства, которое, как известно, проводится Федеральной службой государственной статистики один раз в пять лет. В таблице 2 представлены отчетные данные последних двух сплошных наблюдений за деятельностью малых и средних предприятий в России (по данным за 2010 и 2015 гг.).

Как видно из данных таблицы 2, общая численность зарегистрированных субъектов малого и среднего предпринимательства в анализируемом периоде увеличилась на 9,5\%, составив по 
Таблица 1. Показатели уровня развития малого и среднего предпринимательства в различных странах

\begin{tabular}{|l|c|c|c|}
\hline \multicolumn{1}{|c|}{ Страна } & $\begin{array}{c}\text { Кол-во субъектов малого и } \\
\text { среднего предприниматель- } \\
\text { ства на 1000 жителей, ед. }\end{array}$ & $\begin{array}{c}\text { Доля занятых в секторе } \\
\text { малого и среднего предпри- } \\
\text { нимательства, }\end{array}$ & $\begin{array}{c}\text { Доля субъектов малого и } \\
\text { среднего предприниматель- } \\
\text { ства в ВВП,\% }\end{array}$ \\
\hline Австралия & 40 & 69 & 35 \\
\hline Великобритания & 27 & 35 & 50 \\
\hline Венгрия & 55 & 48 & 27 \\
\hline Канада & 33 & 47 & 47 \\
\hline Малайзия & 21 & 56 & 35 \\
\hline США & 20 & 42 & 60 \\
\hline Чехия & 85 & 51 & 63 \\
\hline ЮАР & 39 & 60 & 21 \\
\hline Япония & 45 & 77 & \\
\hline Россия & 39 & 25 & 35 \\
\hline
\end{tabular}

Источник: Доклад о мерах по развитию малого и среднего предпринимательства в Российской Федерации. URL: http://smb. gov.ru/files/images/Doklad_Minekonomrazvitiya_za_\%202013-2014_gg..pdf

Таблица 2. Динамика основных показателей деятельности малых и средних предприятий по данным сплошного наблюдения за 2010 и 2015 гг.

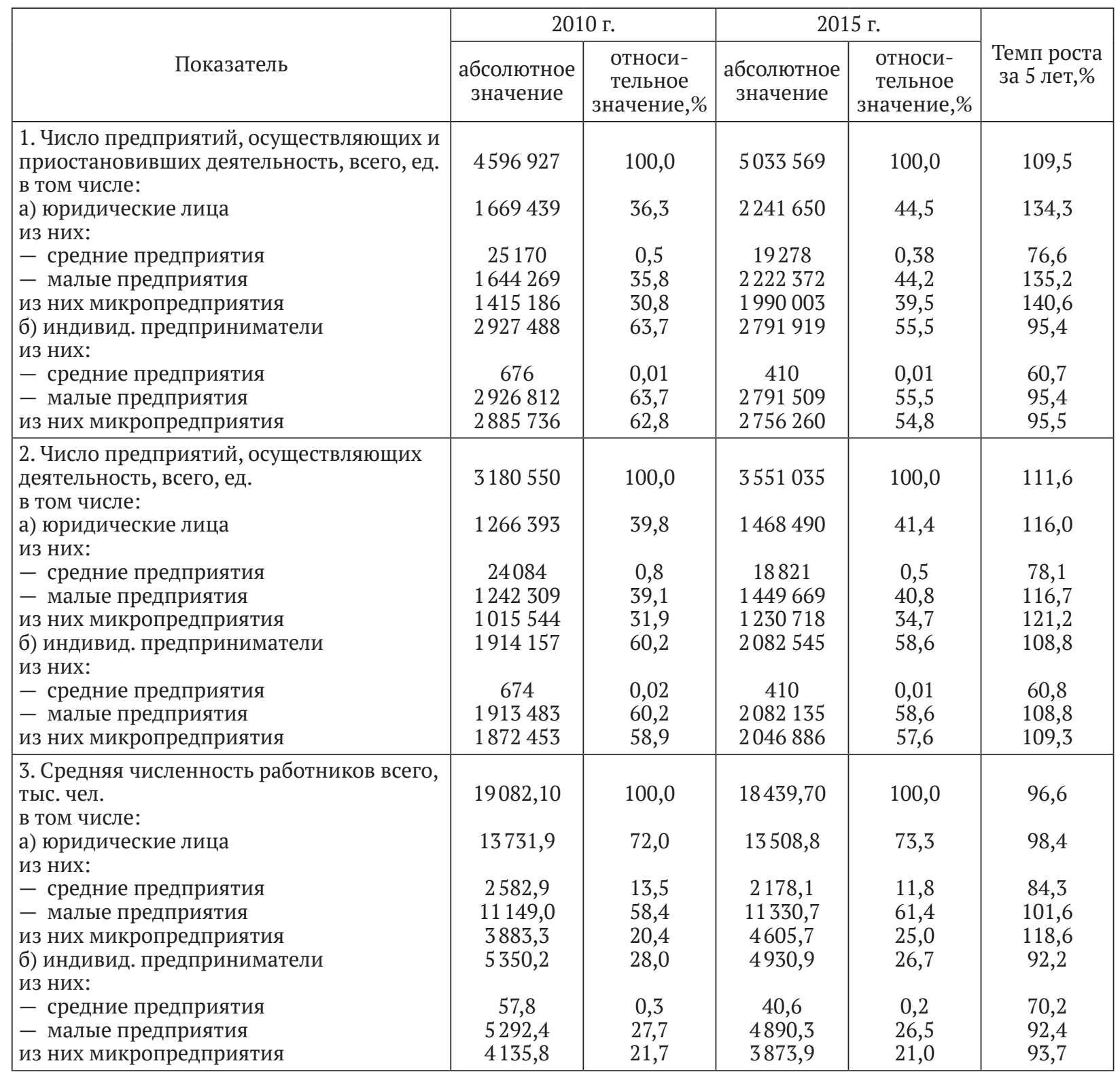




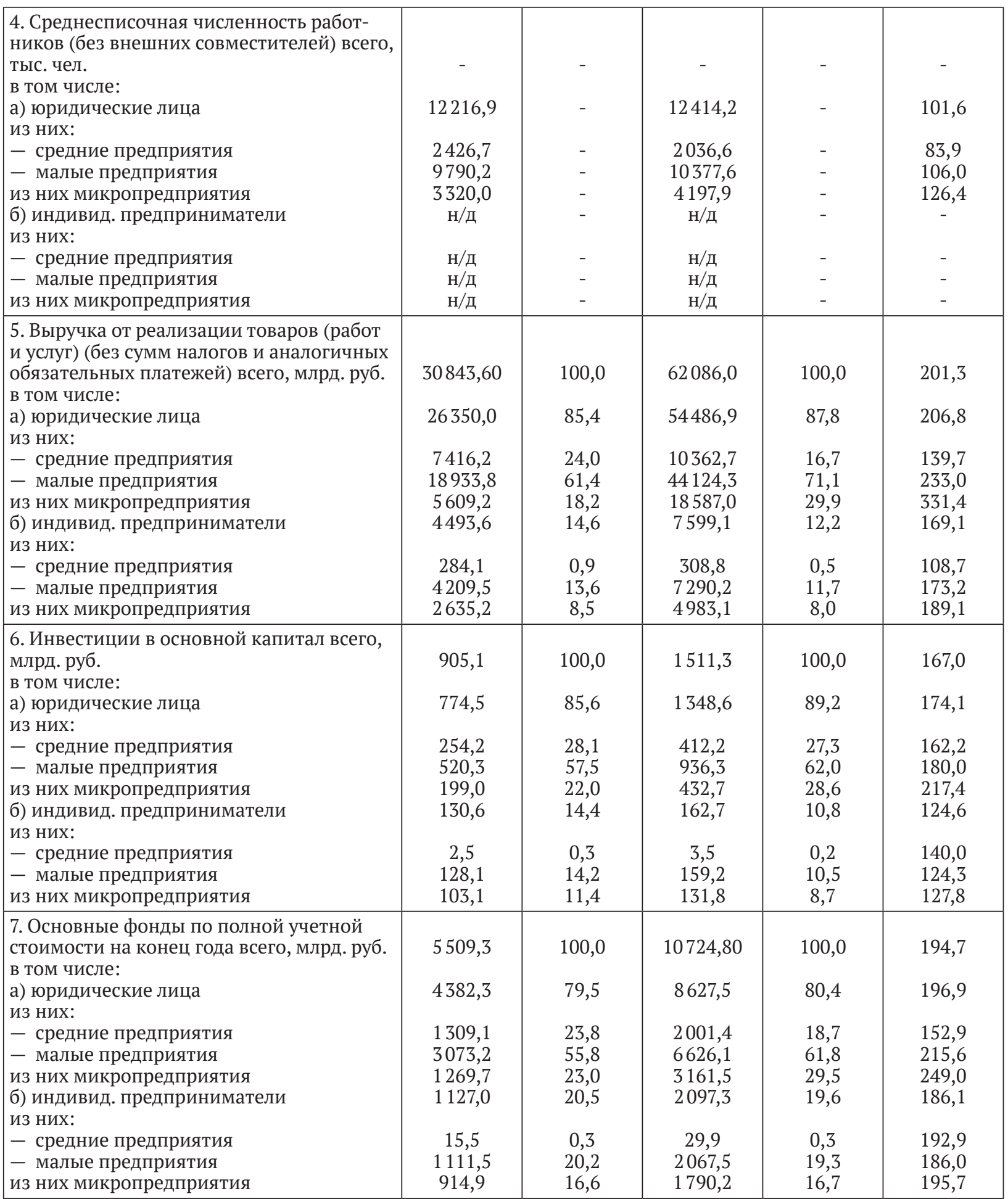

Составлено и рассчитано авторами по данным: Сплошное наблюдение за деятельностью малого и среднего предпринимательства. URL: http://www.gks.ru/free_doc/new_site/business/prom/small_business/per_Mal-i-Sr.htm 
итогам 2015 г. 5033569 предприятий. Из этого количества 3551035 предприятий (70,5\%)не приостанавливали свою деятельность. Их удельный вес в общем количестве предприятий за рассматриваемый период увеличился на $11,6 \%$. Это свидетельствует о незначительном улучшении условий хозяйствования для малых и средних предприятий и повышении их устойчивости.

Однако показатель «средняя численность работников», занятых в секторе малого и среднего предпринимательства, в анализируемом периоде снизился на $3,4 \%$. В наибольшей степени это коснулось предприятий, зарегистрированных в форме индивидуальных предпринимателей (7,8\%), что может быть связано с тем, что им сложнее вести бизнес, «выживать» в условиях недостаточно благоприятного предпринимательского климата. Такое положение дел несомненно не должно оставаться без внимания, поскольку рост численности занятых на малых и средних предприятиях не только способствует решению многих социально-экономических проблем, но и является дополнительным фактором роста ВВП, создаваемого малыми и средними предприятиями.

Для того чтобы произвести оценку темпов роста показателей деятельности субъектов малого и среднего предпринимательства, выраженных в денежном эквиваленте (объем выручки от реализации товаров (работ и услуг), инвестиции в основной капитал, собственные основные средства), необходимо привести эти показатели за 2010 и 2015 годы в сопоставимый вид. С этой целью проведем корректировку данных показателей с учетом динамики индекса потребительских цен за анализируемый период, который ежемесячно рассчитывается и публикуется Федеральной службой государственной статистики.

Руководствуясь теорией статистики для получения индекса потребительских цен за определенный период времени необходимо перемножить все входящие в этот временной промежуток индексы, характеризующие изменение цен в отчетном периоде по сравнению с предыдущим [5]. Рассчитав таким образом индекс потребительских цен за период с января 2011 г. по декабрь 2015 г. включительно $(151,36 \%)$ и скорректировав на него показатели деятельности субъектов малого и среднего предпринимательства, увидим, какими являются значения показателей в сопоставимых условиях
2010 и 2015 гг. (гр. 3 в табл. 3).

Из данных таблицы 3 видно, что инфляция в рассматриваемом периоде оказала существенное влияние на статистику малых и средних предприятий. Так, темп роста выручки малых и средних предприятий в целом за пять лет составил лишь $133 \%$. Отметим, что в разрезе категорий предприятий наибольший рост наблюдался по показателям предприятий, зарегистрированных в форме юридических лиц.

Совокупный темп роста стоимости собственных основных средств малых и средних предприятий составил $128,6 \%$ за анализируемый период, причем рост этого показателя по предприятиям-юридическим лицам превышал аналогичный показатель по предприятиям в форме индивидуальных предпринимателей. Еще в меньшей степени увеличились объемы инвестиций в основной капитал малых и средних предприятий $-110,3 \%$ за пять лет. Причем совокупный рост был обеспечен исключительно предприятиями-юридическими лицами, тогда как у индивидуальных предпринимателей в анализируемом периоде наблюдалось снижение инвестиций в основной капитал на 17,7\%. Между тем инвестиции в основной капитал - важнейший показатель, характеризующий не только финансово-экономическое положение предприятия, его финансовые возможности, но и «настроение» предпринимателей развивать свое дело, их веру в будущее.

Таким образом, результаты проведенного анализа динамики показателей деятельности субъектов малого и среднего предпринимательства свидетельствуют о недостаточности темпов развития этого сектора экономики для достижения задачи, поставленной Президентом в послании Федеральному Собранию. В первую очередь это касается показателя «средняя численность работников», который в анализируемом периоде имел отрицательную динамику. Следовательно, если не предпринять срочных мер, направленных на скорейшее устранение этого явления, достижение заданной Президентом цели (рост численности занятых до 25 млн. человек) не представляется возможным. Относительно оценки темпов роста второго целевого показателя (вклад малых и средних предприятий в ВВП к 2024 г. - 40\%) возникают некоторые трудности, связанные с тем, что Федеральная служба государственной статистики в настоящее время его не публикует. Между тем, как было от- 
Таблица 3. Динамика показателей деятельности субъектов малого и среднего предпринимательства в сопоставимых ценах за пять лет (в ценах 2010 г.)

\begin{tabular}{|c|c|c|c|}
\hline Показатель & 2010 г. & 2015 г. & $\begin{array}{l}\text { Темп роста за } \\
20102015 \text { гг.,\% }\end{array}$ \\
\hline 1 & 2 & 3 & 4 \\
\hline $\begin{array}{l}\text { 1. Выручка от реализации товаров (работ } \\
\text { и услуг) (без сумм налогов и аналогичных } \\
\text { обязательных платежей) всего, млрд. руб. } \\
\text { в том числе: } \\
\text { а) юридические лица } \\
\text { из них: } \\
\text { - средние предприятия } \\
\text { - малые предприятия } \\
\text { из них микропредприятия } \\
\text { б) индивидуальные предприниматели } \\
\text { из них: } \\
\text { - средние предприятия } \\
\text { - малые предприятия } \\
\text { из них микропредприятия }\end{array}$ & $\begin{array}{c}30843,6 \\
26350,0 \\
\\
7416,2 \\
18933,8 \\
5609,2 \\
4493,6 \\
\\
284,1 \\
4209,5 \\
2635,2\end{array}$ & $\begin{array}{c}41018,8 \\
\\
35998,2 \\
\\
6846,4 \\
29151,9 \\
12280,0 \\
5020,5 \\
\\
204,0 \\
4816,5 \\
3292,2\end{array}$ & $\begin{array}{c}133,0 \\
136,6 \\
\\
92,3 \\
154,0 \\
218,9 \\
111,7 \\
\\
71,8 \\
114,4 \\
124,9\end{array}$ \\
\hline $\begin{array}{l}\text { 2. Инвестиции в основной капитал всего, } \\
\text { млрд. руб. } \\
\text { в том числе: } \\
\text { а) юридические лица } \\
\text { из них: } \\
\text { - средние предприятия } \\
\text { - малые предприятия } \\
\text { из них микропредприятия } \\
\text { б) индивидуальные предприниматели } \\
\text { из них: } \\
\text { - средние предприятия } \\
\text { - малые предприятия } \\
\text { из них микропредприятия }\end{array}$ & $\begin{array}{c}905,1 \\
774,5 \\
\\
254,2 \\
520,3 \\
199,0 \\
130,6 \\
\\
2,5 \\
128,1 \\
103,1\end{array}$ & $\begin{array}{c}998,5 \\
\\
891,0 \\
\\
272,3 \\
618,6 \\
285,9 \\
107,5 \\
\\
2,3 \\
105,2 \\
87,1\end{array}$ & $\begin{array}{c}110,3 \\
115,0 \\
107,1 \\
118,9 \\
143,7 \\
82,3 \\
\\
92,5 \\
82,1 \\
84,5\end{array}$ \\
\hline $\begin{array}{l}\text { 3. Основные фонды по полной учетной сто- } \\
\text { имости на конец года всего, млрд. руб. } \\
\text { в том числе: } \\
\text { а) юридические лица } \\
\text { из них: } \\
\text { - средние предприятия } \\
\text { - малые предприятия } \\
\text { из них микропредприятия } \\
\text { б) индивидуальные предприниматели } \\
\text { из них: } \\
\text { - средние предприятия } \\
\text { - малые предприятия } \\
\text { из них микропредприятия }\end{array}$ & $\begin{array}{l}5509,3 \\
4382,3 \\
1309,1 \\
3073,2 \\
1269,7 \\
1127,0 \\
\\
15,5 \\
111,5 \\
914,9\end{array}$ & $\begin{array}{l}7085,6 \\
5700,0 \\
1322,3 \\
4377,7 \\
2088,7 \\
1385,6 \\
19,8 \\
1365,9 \\
1182,7\end{array}$ & $\begin{array}{l}128,6 \\
130,1 \\
101,0 \\
142,4 \\
164,5 \\
122,9 \\
127,4 \\
122,9 \\
129,3\end{array}$ \\
\hline
\end{tabular}

Составлено и рассчитано авторами по данным: Сплошное наблюдение за деятельностью малого и среднего предпринимательства. URL: http://www.gks.ru/free_doc/new_site/business/prom/small_business/per_Mal-i-Sr.htm

Таблица 4. Целевые ориентиры роста показателей деятельности малых и средних предприятий на 2018-2023 гг.

\begin{tabular}{|l|c|c|c|c|c|c|c|}
\hline \multicolumn{1}{|c|}{ Показатель } & 2017 г. & 2018 г. & 2019 г. & 2020 г. & 2021 г. & 2022 г. & 2023 г. \\
\hline $\begin{array}{l}\text { Доля субъектов малого и } \\
\text { среднего предприниматель- } \\
\text { ства в ВВП, \% }\end{array}$ & 19,90 & 22,36 & 25,12 & 28,22 & 31,70 & 35,61 & 40,00 \\
\hline $\begin{array}{l}\text { Число занятых на малых и } \\
\text { средних предприятиях, млн. } \\
\text { человек }\end{array}$ & 19,00 & 19,88 & 20,82 & 21,79 & 22,81 & 23,88 & 25,00 \\
\hline
\end{tabular}

Составлено и рассчитано авторами 
мечено ранее, по оценкам Минэкономразвития в 2014 г. доля малых и средних предприятий в ВВП составляла 21\%, а в 2017 г. выросла до 22,3\% (ежегодный темп прироста - 2,03\%).

Вместе с тем, для достижения поставленной Президентом цели в 40\% ВВП к 2026 году необходимо обеспечить ежегодный темп прироста последующие шесть лет на уровне 12,34\%. Соответственно для увеличения численности занятых в секторе малого и среднего предпринимательства до 25 млн. человек к 2024 г. ежегодный темп прироста этого показателя должен быть не менее 4,68\% (табл. 4).

Таким образом, темпы роста основных показателей деятельности малого и среднего предпринимательства за анализируемый период существенно отстают от показателей, необходи- мых для достижения поставленных Президентом целевых ориентиров, а именно:

- по показателю «доля малого и среднего предпринимательства в общем объеме ВВП страны» ежегодные темпы прироста должны быть не менее $12,34 \%$ вместо достигнутых за период с 2014 по 2017 гг. 2,03\%;

- по показателю «число занятых на малых и средних предприятиях, млн. человек» ежегодные темпы прироста должны достигнуть 4,68\% вместо снижения по этому показателю, которое имело место в периоде с 2010 по 2015 гг.

На основе этих данных необходимо устанавливать плановые задания регионам по развитию малого и среднего предпринимательства на шестилетний период.

\section{Библиографический список}

1. Путин В.В. Послание президента Федеральному Собранию. 1 марта 2018 г. [Электронный ресурс] / В.В. Путин // Президент России: офиц. сайт. URL: http://kremlin.ru/events/president/news/56957.

2. Доклад о мерах по развитию малого и среднего предпринимательства в Российской Федерации. URL: http:// smb.gov.ru/files/images /Doklad_Minekonomrazvitiya_za_\%202013-2014_gg..pdf.

3. Доклад об итогах деятельности Минэкономразвития России за 2017 год и задачах на 2018 год. URL: http://economy.gov.ru /wps/wcm/connect/cfdd9d90-be57-4054-b81aeaf3b3d009b1/doklad20172018.pdf? MOD=AJPERES\&CACHEID=cfdd9d90-be57-4054-b81a-eaf3b3d009b1.

4. Сплошное наблюдение за деятельностью малого и среднего предпринимательства. URL: http://www.gks.ru/ free_doc/new_site/business/prom/small_business/per_Mal-i-Sr.htm.

5. Индексы потребительских цен по Российской Федерации в 19912018 гг. URL: http://www.gks.ru/free_doc / new_site/prices/potr/tab-potr1.htm.

6. Буров В.Ю. Малое предпринимательство в пространственном развитии региона / В.Ю. Буров // Вестник Бурятского государственного университета. 2015. № 2. С. 7883.

7. Буров В.Ю. Особенности влияния государства на экономическую деятельность субъектов малого предпринимательства в современной России [Электронный ресурс] / В.Ю. Буров, В.В. Серватинский, А.У. Ортыков // BAIKAL RESEARCH JOURNAL. 2017. T. 8, № 1. URL: http://brj-bguep.ru/reader/article.aspx?id=21379.

8. Буров В.Ю. Формирование и проведение мониторинга состояния малого предпринимательства на региональном уровне / В.Ю. Буров // Известия Байкальского государственного университета. 2016. Т. 26, № 5. С. 731738

9. Валеев Т.А. Основные направления государственной поддержки субъектов малого и среднего предпринимательства / Т.А. Валеев // Вестник Нижегородской правовой академии. 2018. № 15 (15). С. 6061.

10. Грибанова Н.С. Основные положения поддержки в развитии малого и среднего бизнеса России / Н.С. Грибанова, Н.Н. Грибанова // Baikal Research Journal. 2015. T. 6, № 5. DOI: 10.17150/2411-6262.2015.6(5).1.

11. Филобокова Л.Ю. Управление налоговыми рисками в малом предпринимательстве / Л.Ю. Филобокова // Управление финансовыми рисками. 2015. № 3. С. 228236.

12. Рыков В.М. Снижение инвестиционной активности малого и среднего бизнеса в условиях кризиса / В. М. Рыков, Л.М. Дулина // Baikal Research Journal. 2016. Т. 7, № 6. DOI: 10.17150/2411-6262.2016.7(6).11. 